\title{
A Rare Case of Perianal Langerhans Cell Histiocytosis and Concurrent Right Abdominal Xanthogranuloma
}

\author{
David Chirikian, Matthew Golden, Nathan Baumgarten and Nazila Hejazi* \\ Assistant Professor of Pathology, California Northstate University College of Medicine, CA
}

*Corresponding author: Nazila Hejazi, Assistant Professor of Pathology, California Northstate University College of Medicine, CA 95757

\section{ARTICLE INFO \\ Received: 慧 October 29, 2020 \\ Published: 慧 November 09, 2020}

Citation: David Chirikian, Matthew Golden, Nathan Baumgarten, Nazila Hejazi. A Rare Case of Perianal Langerhans Cell Histiocytosis and Concurrent Right Abdominal Xanthogranuloma. Biomed J Sci \& Tech Res 31(5)-2020. BJSTR. MS.ID.005152.

\section{ABSTRACT}

Langerhans Cell Histiocytosis (LCH), commonly referred to as Histiocytosis X, is a rare disorder characterized by proliferation of Langerin/CD1a/S100+ cells. Xanthogranuloma (XG) is a non-Langerhans cell histiocytic proliferative disorder which is negative for Langerin/CD1a. The co-occurrence of Langerhans Cell Histiocytosis and Non-Langerhans Cell Histiocytosis is an unusual event. We are reporting a 59-year-old man with a rare case of perianal LCH who later presented with Xanthogranuloma of the right abdominal skin. To our knowledge, this is the first documented case of concurrent LCH and XG with no prior history of chemotherapy.

Abbreviations: LCH: Langerhans Cell Histiocytosis; XG: Xanthogranuloma; JXG: Juvenile Xanthogranuloma; ECD: Erdheim-Chester Disease

\section{Introduction}

Langerhans Cell Histiocytosis (LCH) is a rare neoplastic disorder characterized by the proliferation of Langerin (CD207) positive, CD1a positive, and S100 positive myeloid progenitor cells which contain Birbeck granules on microscopic analysis (Figure 1). LCH can infiltrate most organs, classically producing osteolytic bone lesions (77\%), an erythematous popular rash (39\%), and/ or oral lesions [1]. LCH is most commonly seen in children (4-5 children per million annually) [2]. Although adults, more frequently men with a mean age of onset of 33-35 years-old [3], may be affected as well (1-2 adults per million annually) [4]. Multisystem $\mathrm{LCH}$, which often leads to dysfunction of the liver, spleen, and bone marrow, has a poor prognosis even with optimal treatment [5]. Xanthogranuloma (XG) is a non-Langerhans cell histiocytic proliferative disorder that is characterized by one or more benign, self-containing cutaneous nodules typically appearing in infancy [6]. There are no well described nodular predilection sites for adult XG [7]. However, juvenile xanthogranuloma (JXG) predilection sites include the head and neck, but cases of extracutaneous, truncal, and extremital nodules have also been reported $[6,8]$. The occurrence of concurrent Langerhans cell histiocytosis and non-Langerhans cell histiocytosis is an unusual event. There is a known, complex relationship between the development of LCH and XG. However, the histogenesis of both disorders is not well defined. Here we report a 59-year-old man with a rare case of perianal LCH who presented two months later with XG of the right abdomen.

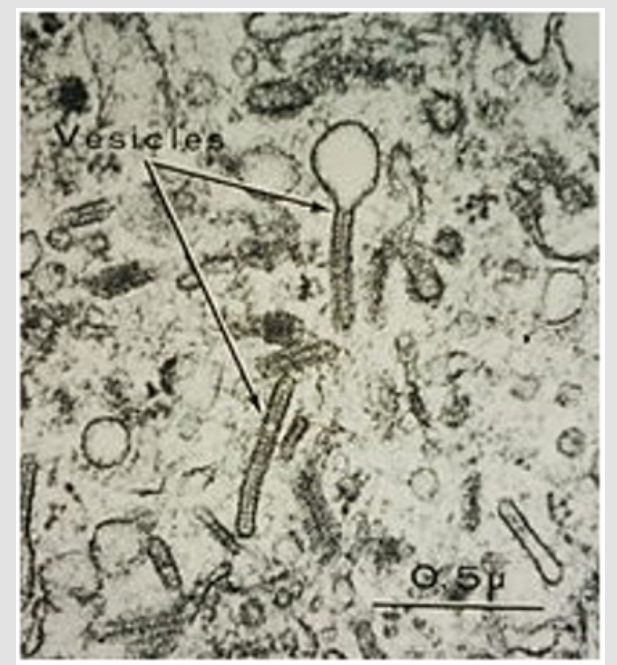

Source: Yale Rosen from USA - Langerhans cell histiocytosis - Birbeck granules, CC BY-SA 2.0.

Figure 1: Electron microscope imaging of Birbeck Granules within the cytoplasm of Langerhans cells. 


\section{Case Report}

A 59-year-old male initially presented to the clinic with anal discharge. Physical examination revealed an infected $2.5 \times 2.0 \mathrm{~cm}$ perianal mass with surface ulceration. The mass was excised and processed. The gross examination revealed a skin covered mass. Margins were inked and specimen was entirely submitted in 4 cassettes. Hematoxylin and eosin stained slides showed skin with surface ulceration and sheaths of infiltrative histiocytic-like cells with nuclear folding, intra-nuclear grooves, and abundant background eosinophils (Figure 2). Additionally, tumor cells penetrated the subcutaneous tissue and were present at resection margin. Mitotic figures were present with approximately 10 mitoses per 10HPF. On immunohistochemistry staining with review of appropriate control tissue, the tumor cells were-positive for Langerin (CD207), CD1a, S100, and CD68 (Table 1). A positive BRAF stain was also obtained at an outside institute, indicating a BRAF V600E mutation. Given the positive stains for Langerin, CD1a, S100, CD68 (Figures 3-6) and negative stains for pancytokeratin (Figure 7), a diagnosis of LCH was suspected. After excision of the mass, the wound was left open to drain and the lesion resolved over a few months without any further intervention or treatment.

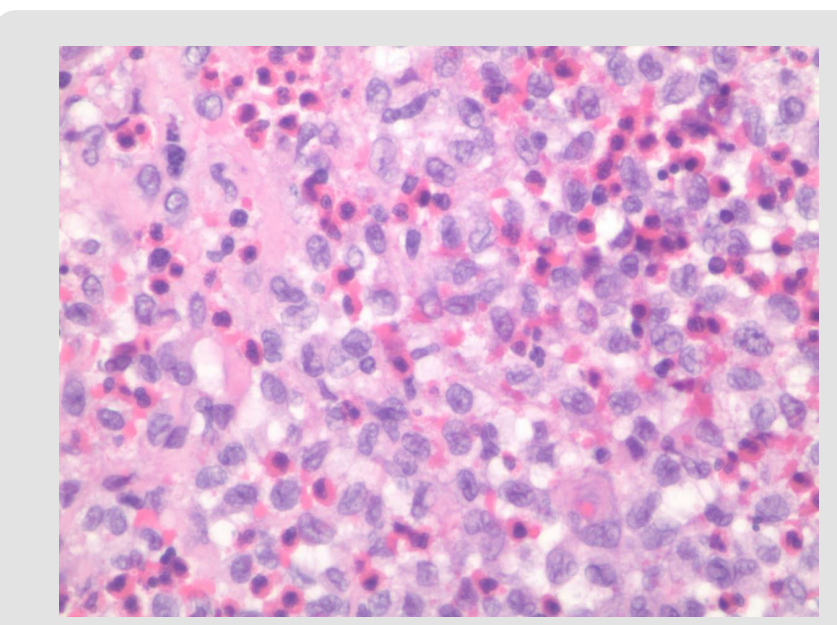

Figure 2: Hematoxylin and eosin stained, 40x, the perianal mass showed sheaths of histiocytic-like cells with nuclear folding, intra-nuclear grooves and abundant background eosinophils.

Table 1: Immunohistochemical findings of the excised $2.5 \times 2.0$ cm perianal mass.

\begin{tabular}{|c|c|}
\hline Stain & Result \\
\hline Langerin (CD 207) & Strongly and Diffusely Positive \\
\hline CD1a & Strongly and Diffusely Positive \\
\hline S100 & Strongly and Diffusely Positive \\
\hline CD68 & Diffusely Positive \\
\hline BRAF & Positive \\
\hline P16 & Moderately and Diffusely Positive \\
\hline Pancytokeratin & Negative \\
\hline EMA & Negative \\
\hline CD20 &
\end{tabular}

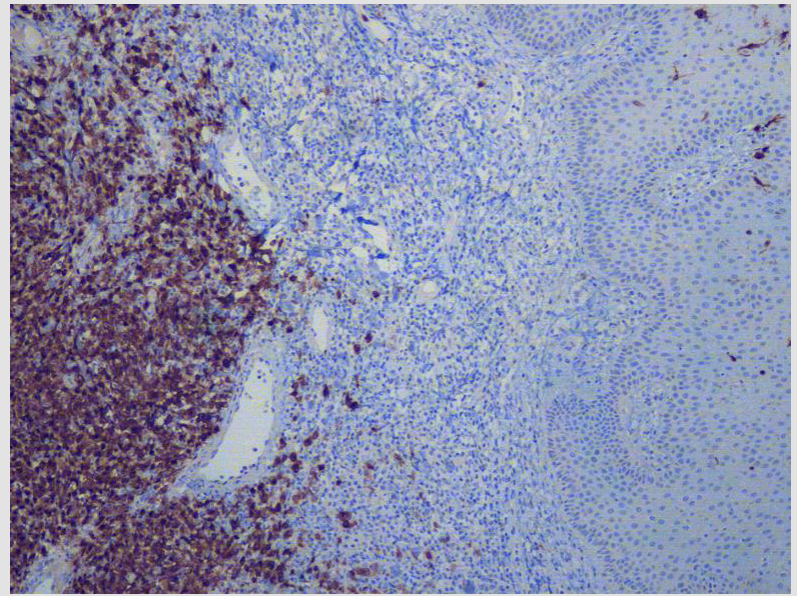

Figure 3: Langerin (CD207): Immunohistochemical Stain; Perianal Mass, Strongly and Diffusely Positive in Tumor Cells and Few Positive Internal Control Langerhans Cells with Exocytosis in Overlying Skin Squamous Epithelium.

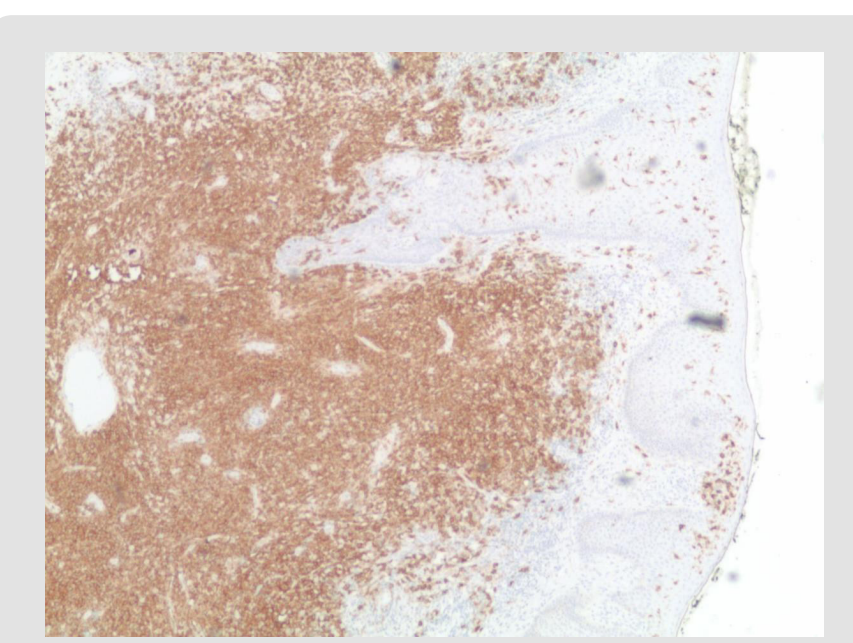

Figure 4: CD1a + Immunohistochemical Stain; Perianal Mass, Strongly and Diffusely Positive in Tumor Cells.

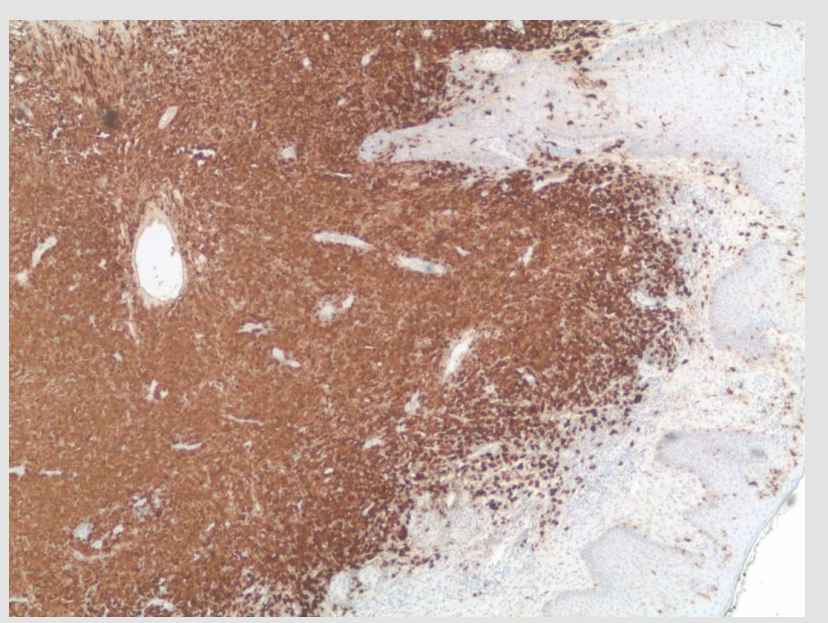

Figure 5: S100+; Immunohistochemical Stain; Perianal Mass, Strongly and Diffusely Positive in Tumor Cells. 


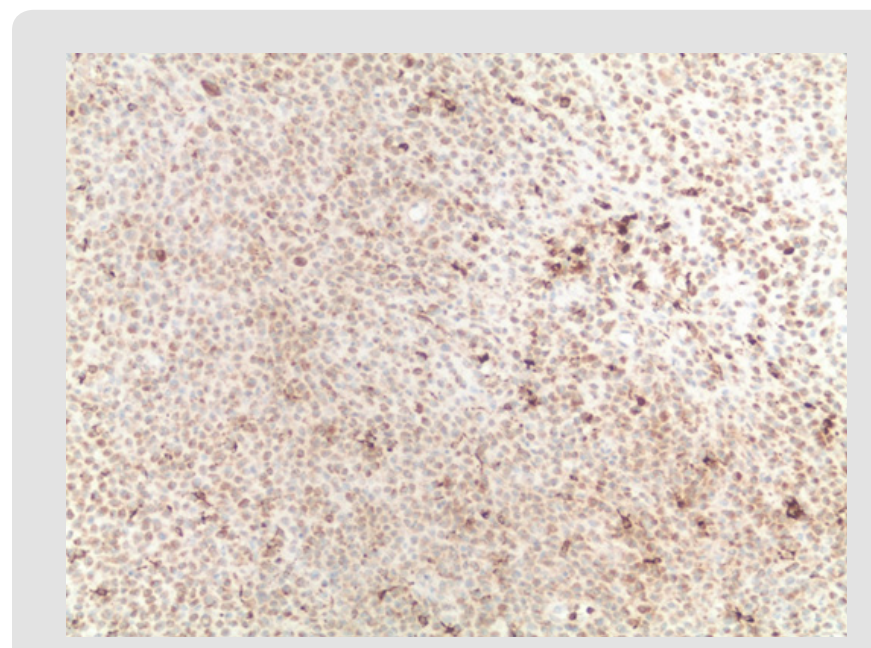

Figure 6: CD68+ Immunohistochemical Stain; Perianal Mass, Strongly and Diffusely Positive in Tumor Cells.

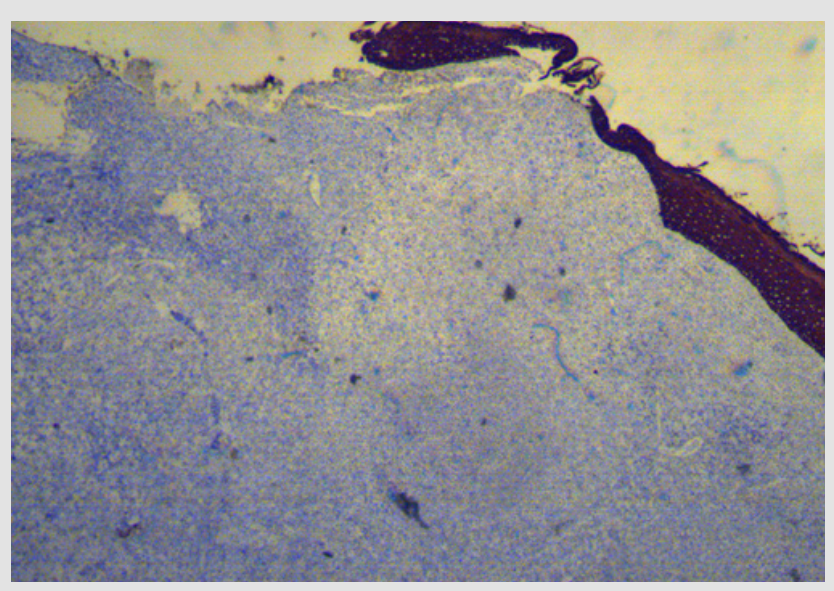

Figure 7: Pancytokeratin Immunohistochemical Stain; Perianal Mass, Negative in Tumor Cells with Positive Internal Control of Overlying Squamous Epithelium.

Two months later, the same patient presented to a different clinic with a right abdominal cutaneous lesion. A $0.4 \mathrm{~cm}$ punch biopsy of the lesion revealed a nodular infiltrate of cells with abundant pale homogenous appearing eosinophilic cytoplasm with moderately large oval nuclei and interspersed lymphocytes, neutrophils and eosinophils. Some cells with lipidized cytoplasm were also noted. On immunohistochemistry, the right abdominal cutaneous lesion stained negative for Langerin (CD207), negative for CD1a, faintly positive for BRAF, and positive for Factor XIIIa (Table 2). These immunohistochemical findings suggest a diagnosis of adult xanthogranuloma. The patient was later lost to follow-up.

Table 2: Immunohistochemical findings of the biopsied right abdominal cutaneous lesion.

\begin{tabular}{|c|c|}
\hline Stain & Result \\
\hline Langerin (CD207) & Negative \\
\hline CD1a & Negative \\
\hline BRAF & Faintly Positive \\
\hline Factor XIIIa & Positive \\
\hline
\end{tabular}

\section{Discussion}

The pathophysiology of LCH is not well understood. LCH may spontaneously regress, suggesting a reactive nature, however monoclonal populations point towards a neoplastic condition. Biopsy of LCH reveals mixed cellularity with Langerhans cells, eosinophils, neutrophils, and lymphocytes. In addition to staining positive for CD1a, S100, and Langerin/CD207, 57\% of LCH are positive for BRAF V600E mutations which is associated with higher risk of disease $[9,10]$. Langerhans cells contain Birbeck granules (Figure 1), rod-shaped organelles commonly described as "tennis rackets". LCH most often presents as a single system disease, most commonly involving flat bones of the axial skeleton (ribs, pelvis, and skull) [11]. Single system LCH has also been described as involving the skin, thyroid, lymph nodes, thymus, or pituitary gland. Skull or pituitary gland involvement may present with Diabetes Insipidus [2]. Lungs are also commonly involved in adult LCH and $90 \%$ of pulmonary LCH cases are associated with smoking $[12,13]$. Additionally, perianal LCH has been seen in adults [1418], but this represents an uncommon site for LCH involvement. LCH may be difficult to diagnose without immunohistochemistry as it can involve many organs and present similarly to diseases such as Erdheim-Chester disease (ECD), Langerhans Cell sarcoma, multiple myeloma, and Juvenile Xanthogranuloma (JXG). ECD is a rare non-Langerhans cell histocyte disorder that may present with similar bony infiltration, a BRAF V600E mutation, and cutaneous lesions [19]. The patient's perianal lesion was positive for BRAF V600E. However, ECD is negative for CD1a and LangerinIn this patient, Langerhans cell sarcoma was also ruled out due to lack of required threshold for cytological atypia. Additionally, multiple myeloma can present with similar lytic lesions within flat bones of the axial skeleton and was subsequently ruled out with immunohistochemistry.

JXG is another rare non-Langerhans cell histiocytic disorder characterized by one or more yellow, red papulonodular lesions, typically presenting in infancy, that stain negative for Langerhans cell markers (Langerin/CD207, CD1a, S100) and positive for Factor XIIIa [20]. Given the patient's immunohistochemical findings, a diagnosis for xanthogranuloma of the right abdomen was made. The occurrence of concurrent Langerhans cell histiocytosis and non-Langerhans cell histiocytosis is an unusual event. While rare, cases of developing xanthogranuloma (XG) as a sequela of LCH have been reported in children [21] and as a consequence to chemotherapy in adults [22-24]. The patient in this case report was not given a chemotherapeutic agent for treatment of his LCH. As far as we know, this is the first known case of adult perianal LCH and concurrent XG in the literature.

\section{Conclusion}

Although rare, LCH can involve uncommon sites including the perianal region. Immunohistochemistry work-up is needed in order to differentiate LCH from other histiocytic lesions such as Erdheim-Chester disease, Langerhans Cell sarcoma, multiple 
myeloma, and Juvenile Xanthogranuloma. To our knowledge, this is the first documented case of perianal LCH and xanthogranuloma appearing concurrently.

\section{Data Availability}

No other data or other supporting materials were collected or used for this report.

\section{Conflicts of Interest}

The authors have no conflict of interest.

\section{References}

1. Grois N, Pötschger U, Prosch H, Minkov M, Arico M, et al. (2006) Risk factors for diabetes insipidus in Langerhans cell histiocytosis. Pediatric Blood and Cancer 46(2): 228-233.

2. Baumgartner I, Von Hochstetter A, Baumert B, Luetolf U, Follath F (1997) Langerhans-cell histiocytosis in adults. Med Pediatr Oncol 28(1): 9-14.

3. Arico M, M Girschikofsky, T Généreau, C Klersy, K Mc Clain, et al. (2003) Langerhans cell histiocytosis in adults. Report from the International Registry of the Histiocyte Society. Eur J Cancer 39(16): 2341-2348.

4. Salotti JA, Nanduri V, Pearce MS, Parker L, Lynn R, et al. (2009) Incidence and clinical features of Langerhans cell histiocytosis in the UK and Ireland. Archives of Disease in Childhood 94(5): 376-380.

5. Gadner H, Milen Minkov, Nicole Grois, Ulrike Pötschger, Elfriede Thiem, et al. (2013) Therapy prolongation improves outcome in multisystem Langerhans cell histiocytosis. Blood 121(25): 5006-5014.

6. Hernandez Martin A, Baselga E, Drolet BA, Esterly NB (1997) Juvenile xanthogranuloma. J Am Acad Dermatol 36(3 Pt 1): 355-369.

7. Burgdorf WH (1997) The histocytosis. In Elder D, Elenitsas R, Jaworsky C, Johnson B Jr (Eds.) Lever's Histopathology of the skin ( ${ }^{\text {th }}$ Edn.), Lippincott- Raven Publishers, Philadelphia, USA: 607-610

8. Pajaziti L, Hapçiu SR, Pajaziti A (2014) Juvenile xanthogranuloma: a case report and review of the literature. BMC Res Notes 7: 174.

9. Satoh T, Smith A, Sarde A, Lu HC, Mian S, et al. (2012) Correction: B-RAF Mutant Alleles Associated with Langerhans Cell Histiocytosis, a Granulomatous Pediatric Disease. PLOS ONE 2012 7(6): 10

10. Berres ML, Har Lim KP, Peters T, Price J, Takizawa H, et al. (2014) BRAFV600E expression in precursor versus differentiated dendritic cells defines clinically distinct LCH risk groups. Journal of Experimental Medicine 211(4): 669-683

\section{ISSN: 2574-1241}

DOI: $10.26717 /$ BJSTR.2020.31.005152

Nazila Hejazi. Biomed J Sci \& Tech Res

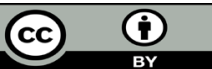

This work is licensed under Creative Commons Attribution 4.0 License

Submission Link: https://biomedres.us/submit-manuscript.php
11. Stull MA, Kransdorf MJ, Devaney KO (1992) Langerhans cell histiocytosis of bone. Radiographics 12: 801-823.

12. Vassallo R, Ryu JH, Schroeder DR, Decker PA, Limper AH (2002) Clinical outcomes of pulmonary Langerhans'-cell histiocytosis in adults. N Engl J Med 346(7): 484-490

13. Travis WD, Borok Z, Roum JH, Zhang J, Feuerstein I, et al. (1993) Pulmonary Langerhans cell granulomatosis (histiocytosis X). A clinicopathologic study of 48 cases. Am J Surg Pathol 17(10): 971-986.

14. Poppe LM, Müller PA, Poppe H, Bröcker EB, Ugurel S, et al. (2013) Chronic perianal ulceration as the initial symptom of Langerhans cell histiocytosis in adults. Eur J Dermatol 23(4): 551-552.

15. Piccinno R, Passoni E, Carminati G, Caccialanza M (2012) Langerhans cell histiocytosis with perianal localization. Giornale Italiano di Dermatologia e Venereologia 147(2): 220-222.

16. Li R, Lin T, Gu H, Zhou Z (2010) Successful thalidomide treatment of adult solitary perianal Langerhans cell histiocytosis. Eur J Dermatol 20(3): 391-392.

17. Akbayram S, Akgun C, Ozen S, Avni Kaya, Oguz Tuncer, et al. (2009) A case of langerhans cell histiocytosis with anal fistula. Kurume Med J 56(3-4): 79-83

18. Oguzkurt P, Sarialioglu F, Ezer SS, Ince E, Kayaselcuk F, et al. (2008) An uncommon presenting sign of Langerhans cell histiocytosis: focal perianal lesions without systemic involvement. J Pediatr Hematol Oncol 30(12): 915-916.

19. Johnson WT, Patel P, Hernandez A (2016) Langerhans cell histiocytosis and Erdheim-Chester disease, both with cutaneous presentations, and papillary thyroid carcinoma all harboring the BRAF(V600E) mutation. J Cutan Pathol 43(3): 270-275.

20. Misery L, Boucheron S, Claudy AL (1994) Factor XIIIa expression in juvenile xanthogranuloma. Acta Derm Venereol 74(1): 43-44.

21. Hoeger PH, Diaz C, Malone M, Pritchard J, Harper JI (2001) Juvenile xanthogranuloma as a sequel to Langerhans cell histiocytosis: a report of three cases. Clin Exp Dermatol 26(5): 391-394.

22. Tran DT, Wolgamot GM, Olerud J, Hurst S, Argenyi Z (2008) An 'eruptive' variant of juvenile xanthogranuloma associated with langerhans cell histiocytosis. J Cutan Pathol 35(1): 50-54

23. Patrizi A, Neri I, Bianchi F (2004) Langerhans cell histiocytosis and juvenile xanthogranuloma. Two case reports. Dermatology 209(1): 57 61.

24. Strehl JD, Stachel KD, Hartmann A, Agaimy A (2012) Juvenile xanthogranuloma developing after treatment of Langerhans cell histiocytosis: case report and literature review. Int J Clin Exp Pathol 5(7): 720-725.

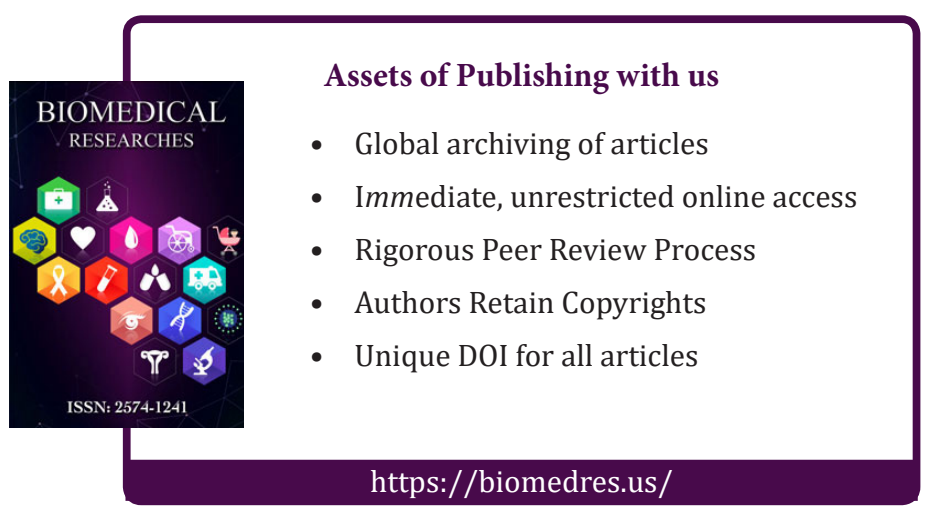

Copyright@ Nazila Hejazi | Biomed J Sci \& Tech Res | BJSTR. MS.ID.005152. 